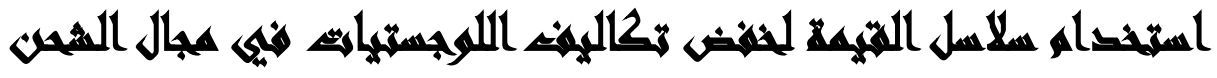

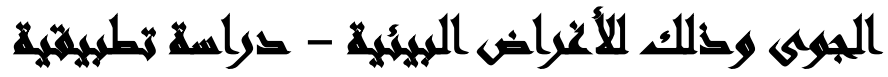

\section{[ro]}

\author{
مصطفى محمد حسن عطية(')- عصافت سيد أحمد حسين عاشور (ץ) (؟)

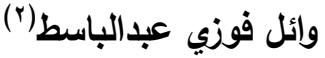 \\ ( ) شركة مصر للطيران للثحن الجوى r) كلية التجارة، جامعة عين شمس ؟
}

\section{المستخلص}

يتمثل الهدف الرئيسى للبحث فى دراسة آنز نطبيق الجيل الثانى من نموذج سلسلة القيمة

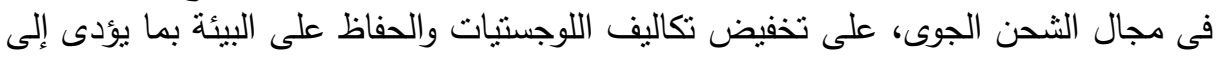

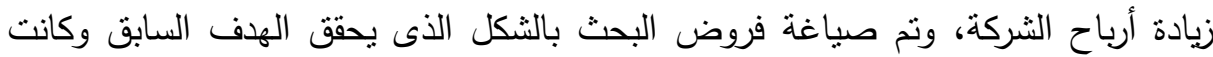
فروض الاراسة كالتالى التى

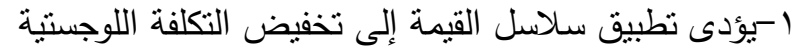

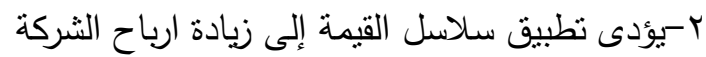

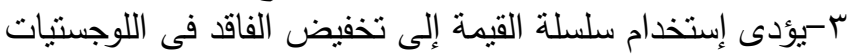
وتم تطبيق الفروض على الثركة (س) للشحن الجوى، واعتمد الباحثون بصفة أساسية التهات

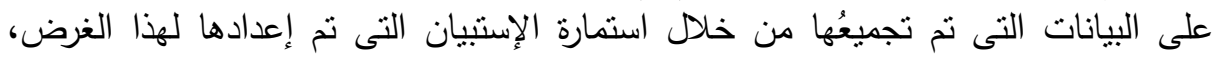

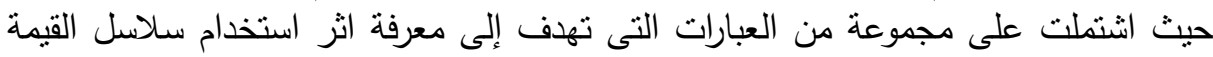

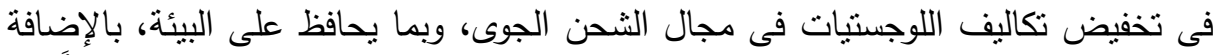

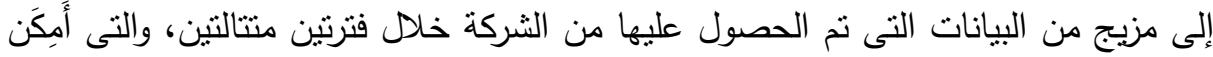

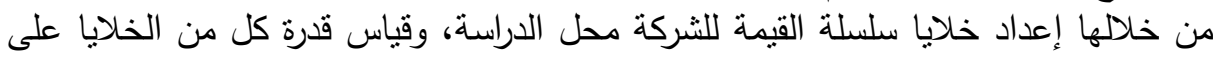

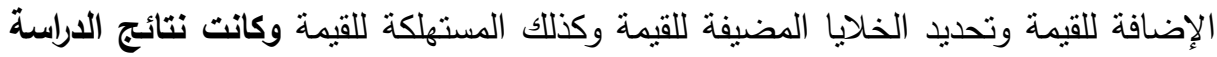

1-كثف تحليل خلايا سلسلة القيمة للثركة (س) عن وجود خلايا مستهلكة للقيمة واخرى

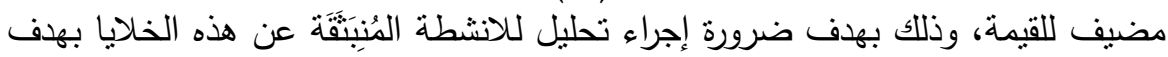

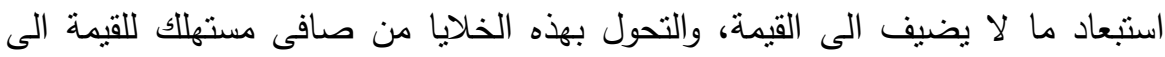
صافى مُنتِج للقيمة. Y-تمثل الخلايا المضيفة للقيمة فى خلية الفراغات الصادرة (جدول \) وخلية الفراغات الواردة

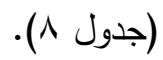


r- من خلال الدراسة السابقة وجد ايضا أن هناك خلايا مستهلكة للقيمة ، وتمنلت تللك الخلايا

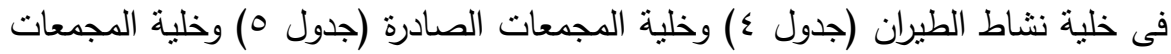

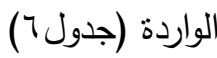

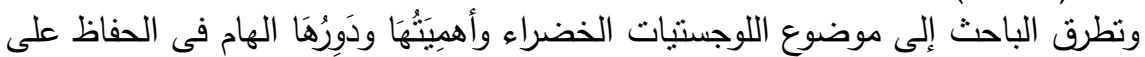

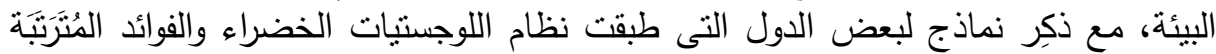

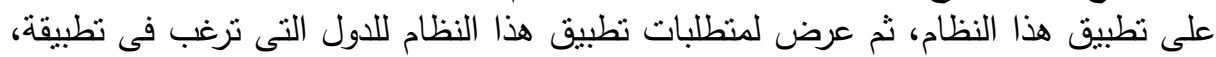

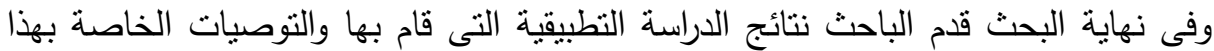

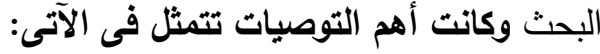

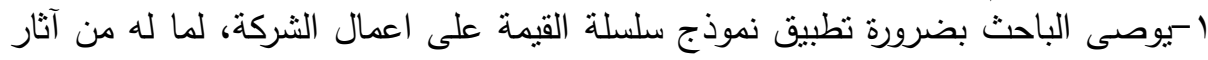

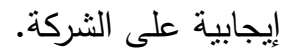
r-Yنبغى الأهتمام بموضوع اللوجستيات الخضراء، لما لها من آنار إيجابية على البيئة المحيطة وعلى المجتمع ككل. r-يجب توافر قاعدة من البيانات فى الثركات، وذللك لإمكانية تطبيق النموذج المقترح على

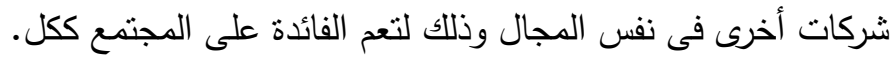

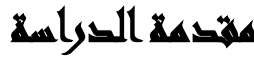

تُعِتَبَر الخدمات اللوجستية عنصر هام في استراتيجيات المنافسة ليست المحلية فقط، بل

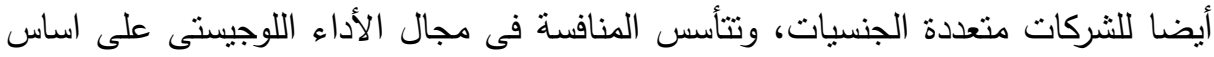
دقة التسليم وجودة الخدمة اليُقَََمة، وهناك بعض الثُركات قد لا تكون على استعداد كامل

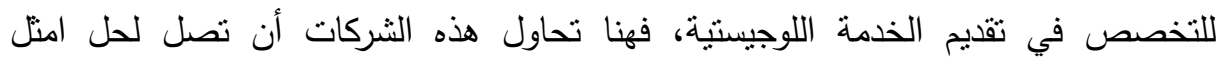
للمشكلات التي تواجهها عن طريق، تعظيم القيمة وتقليل التكلفة بل يجب زيادة الطلب على في لهاهي

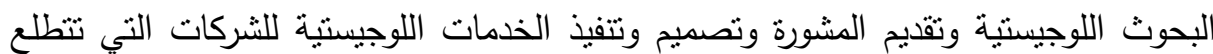

$$
\text { إليها. (Visser,2008,p214). }
$$

وينبغى إتخاذ القرارات اللوجستية التى تؤدى إلى تقليل إنبعاثات عملية النقل حيث النقل يعتبر أكبر مصدر للخطر البيئى فى النظام اللوجيستى، ويمكن أن تؤدى الأنشطة اللوجسنية

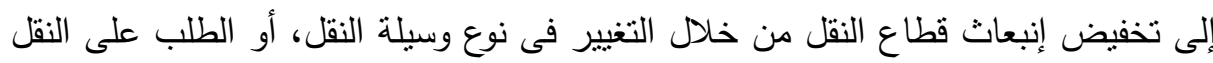
أو استخدام وسيلة نقل معينة، وهذه التحسينات تؤدى إلى تحسن الأداء البيئي وذلك لله آثره على كفاءة وفعالية الخدمات اللوجستية، ولكن يعثقد بعض الثاحنين أن التحول إلى وسيلة نقل 
أقل تلوث للبيئة يؤدى إلى انخفاض فى أداء الخدمات اللوجستية، ولكن هذا الرائ ليس صحيح

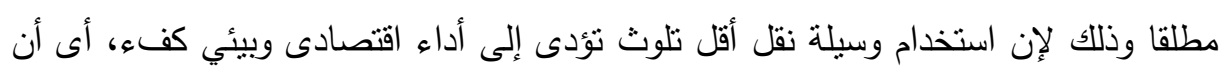

Pazirandeh, Ali\& Jafari, تحسين الاداء البيئ يؤدى إلى زيادة الكفاءة.

(Hamid,2013,p892)

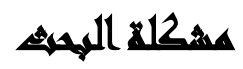

يعتبر موضوع اللوجسنيات لة دور هام ورئيسي في التخطيط والتطبيق والتحكم في تدفق

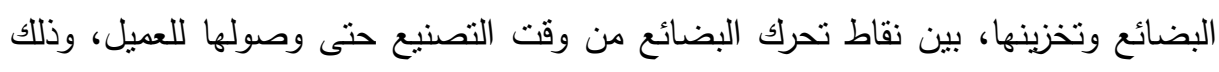
لتحقيق رضاء المستهلك،وتحقيق عائد لاى الثركة العاملة فى هذا المجال .وتزداد هذه ولهن الأهمية

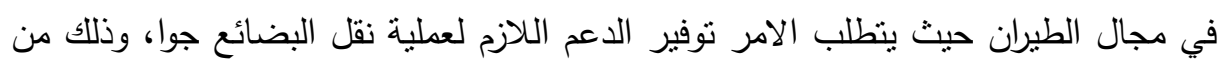

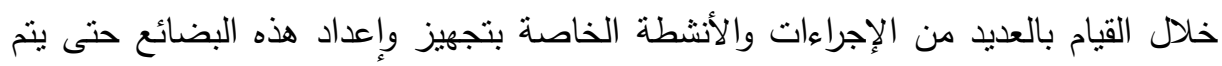

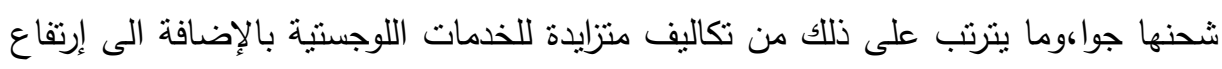
تكلفة النقل الجوى والتكاليف المتزايدة لبرامج حماية البيئة. وتتراوح التكاليف اللوجستية للمُنتنَج

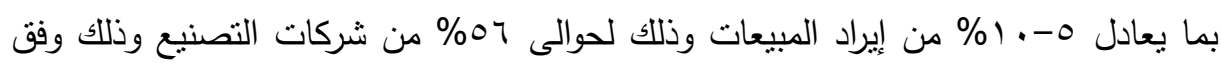
تقرير قام بنشرة إتحاد اللوجستيات الصينى ،بينما تبلغ تكاليف اللوجستيات ما يعادل أقل من من

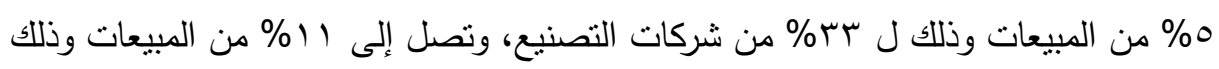

لباقى شركات التصنيع . Song, Hua\&Wang,Lan,2009,p659) ومع ظهور مبدا التمية المستدامة والتى تقوم اساسا على تلبية احتياجات الحاضر دون

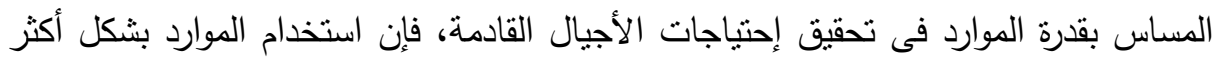

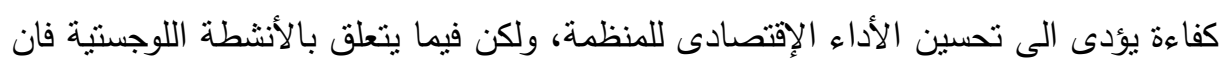

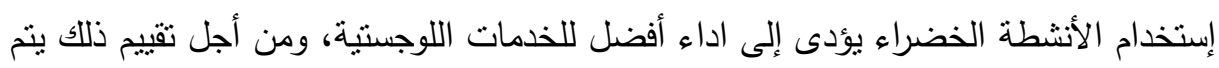
دراسة كفاءة الخدمات اللوجسنية و فعالية الخدمات اللوجسنية. 


\section{فيجب أن تركز إدارة الخدمات اللوجستية على الآتى:}

ا-يجب أن يوفر نظام الخدمات اللوجستية السلعة أو الخدمة الملائمة لإحتباجات العملاء.

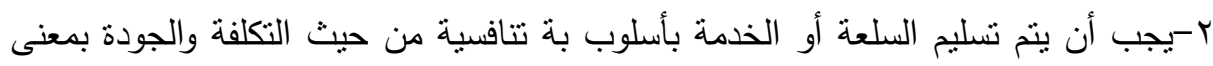

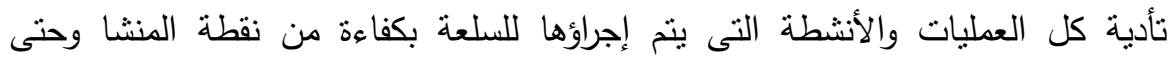

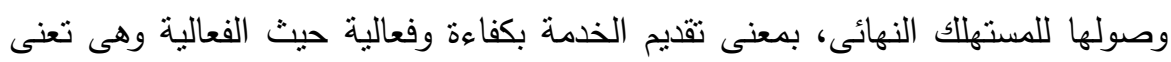
الكم والكيف أى ما هى درجة تحقيق الهدف، بينما يشير مصطلح الكفاءة إلى إستخدام

الموارد بطريقة اقتصادية.( Pazirandeh, Ali\& Jafari, Hamid,2013,p891) ويتعارض وجود هذا الكم المتزايد من التكاليف مع مبدأ تحقيق عائد مرتفع لدى الثركة،

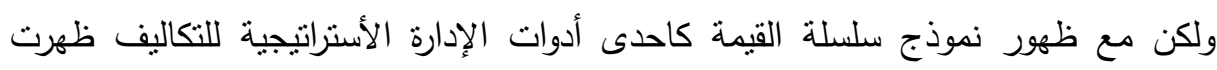
الحاجة إلى إستخدام هذه الأداة فى تخفيض تكاليف اللوجستيات فى مجال الثحن الجوى،وبناءا على ما سبق يمكن صياغة مشكلة البحث فى الأتى:

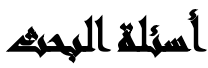

كيف يمكن استخدام سلاسل القيمة بغرض تخفيض نكاليف اللوجستيات والحفاظ على البيئة في مجال الثحن الجوى؟ ويندرج أسفل هذا السؤال الرئيسي مجموعة من الأسئلة الفرعية منها:

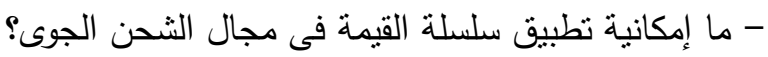

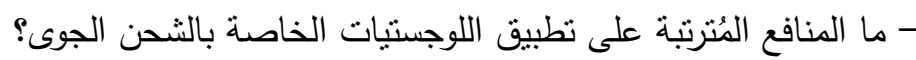

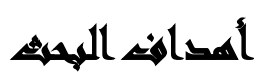

الهدف الرئيسي للبحث هو دراسة تحليلية للعلاقة بين سلاسل القيمة والتكاليف اللوجسنية، وذلك بغرض تخفيض تكاليف اللوجستيات والحفاظ على البيئة في مجال الثحن

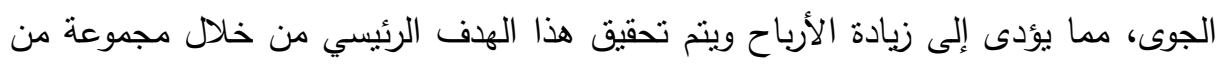

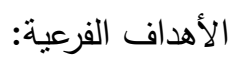


1- تحليل الدور الذي تقوم بة اللوجستيات في مجال الثحن الجوى r- التعرف على كيفية مساهمة سلاسل القيمة في تخفيض التكلفة r- تحليل طبيعة العلاقة بين سلاسل القيمة والتكاليف اللوجستية ع - دراسة كيفية مساهمة اللوجستيات في الحفاظ على البيئة

ويُعِتَبر تطبيق سلسلة القيمة كاحد الأدوات الهامة فى تخفيض التكاليف اللوجسنية

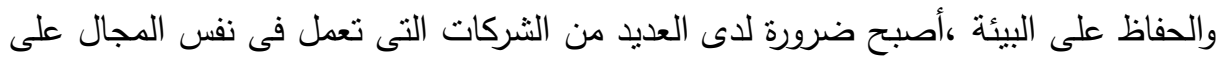
أساس المزايا المُنَّقََعة من تطبيقة على الثركات بما بساهم فى تخفيض التكلفة والحفاظ على

\section{أهمية الهمهث}

ترجع أهمية البحث:

ا- من الناحية العلمية: تتبع أهية دراسة المشكلة المتعلقة بتحليل العلاقة بين سلاسل القيمة والتكاليف اللوجسنية بغرض تخفيض تكلفة اللوجستيات والحفاظ على البيئة في مجال الثحن الجوى، من ضرورة توجية الانتباه إلى قضية اساسية تللك المُنَعَلََة بأهية تحليل العلاقة بين استخدام سلاسل القيمة وتخفيض التكاليف اللوجستية في مجال الشحن الجوى،ومن ثم نوجيه جهود البحث والتطوير لمواجهة تللك المشكلة. التعامل مع موضوع اللوجستيات الخضراء من منظور إدارى حديث، وهو تطبيق نظام اللوجستيات الخضراء على الثحن الجوى، وذلك للاستفادة من تطبيقة وفتح اسواق جديدة وتحسين صورة الثركة نتيجة هذا التطبيق.

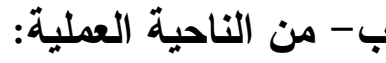

- دعم قدرة الثركة التي تطبق نظام سلاسل القيمة في مجال الثحن الجوى ودور سلاسل القيمة في مجال خفض تكاليف اللوجستيات والحفاظ على البيئة في مجال الثحن الجوى لئل

$$
\text { بما يؤدى إلى زيادة الأرباح. }
$$

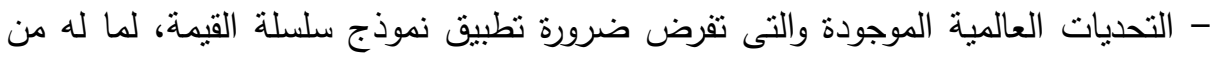
آثار إيجابية فى تخفيض تكاليف اللوجسنيات وبالتالى زيادة أرباح الثركة نتيجة التطبيق

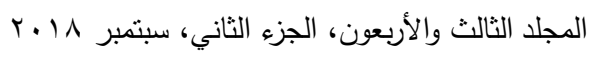


- الحفاظ على مبدأ التتمية المستدامة من خلال تطبيق اللوجستيات الخضراء واللوجستيات العكسية،بما يحافظ على البيئة ويضمن حقوق الأجيال القادمة.

\section{مغرون الصراسمة}

تتمثل فروض الدراسة فيما يلي:

-توجد علاقة ذات دلالة معنوية بين تطبيق سلاسل القيمة و تخفيض التكلفة اللوجستية

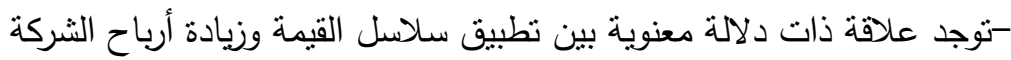
-توجد علاقة ذات دلالة معنوية بين تطبيق سلسلة القيمة و تخفيض الفاقد فى اللوجستيات

\section{التراسايت المايري}

أولاً: دراسات باللغة العربية:

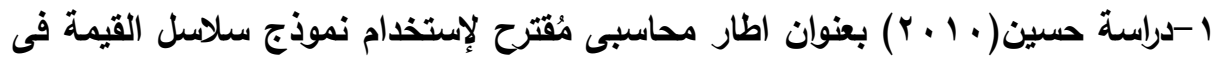

تطوير تقييم استراتيجيات الإستثمار فى الوحدات الاقتصادية - دراسة تطبيقية

تناولت هذه الارلسة أحد الششاكل الهامة والخاصة بتطوير عملية تقييم استراتيجيات الإستتمار فى الوحدات الاقتصادية من خلال نموذج سلاسل القيمة، حيث تحدثت الدراسة عن لنه الإطار الفكرى لنموذج سلاسل القيمة، والكثف عن مكوناتة المُختلفة والفوائد الرئيسية من بناء وتطبيق نموذج سلاسل القيمة فى الوحدات الاقتصادية،ثم تحدثت الدراسة عن تقييم إستراتيجيات الاستثمار من المنظور التقليدى، وكيفية استخدام وتوظيف المنهج الفكرى لنموذج سلاسل القيمة فى نطوير ميكانيكية تقييم إستراتيجيات الاستثمار ،ومن خلال الدراسة النطبيقية

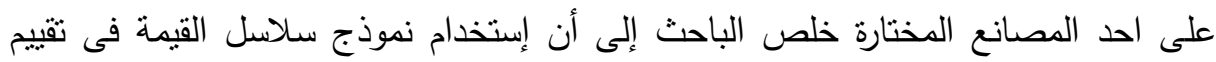

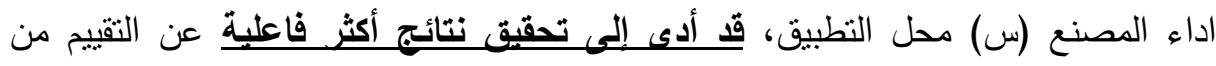
منظورة التقليدى،ويلاحظ الباحث أن هذه الدراسة ركزت على إستخدام نموذج سلاسل القيمة

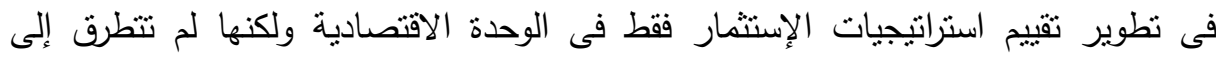


جوانب اخرى هامة فى العملية الانتاجية منل مفهوم اللوجستيات ودورها الهام فى الوجدة

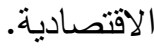

r-دراسة درويش(7 1 • Y) بعنوان إطار مقترح لقياس اتجاهات محاسب التكاليف نحو آثر

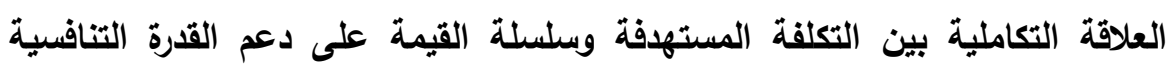

للشركات المصرية(دراسة ميدانية)

تناولت هذه الدراسة ضرورة نَبنِى نُظم مختلفة لإدارة التكلفة فى محاولة للسيطرة على السوق، ومن هذه النُطم كلا من نظام التكلفة المُسنَّهدفة وسلسلة القيمة، حيث هدفت الدراسة إلى عرض تقنيات التكامل بين كل من التكلفة المستهدفة ، سلسلة القيمة، بإعتبارها من أهم المُستَجَدات فى محاسبة التكاليف، بيان مدى التكامل والترابط بين تللك التقنيات واثرة فى خدمة الثركات المصرية فى تحقيق اهدافها التنافسية ، وتم فى هذا البحث قياس مدى تطبيق كل

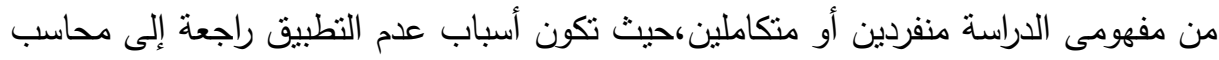

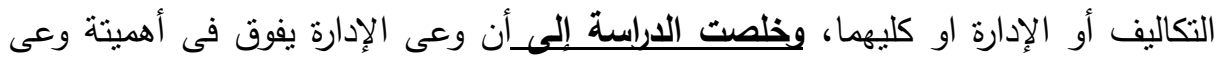

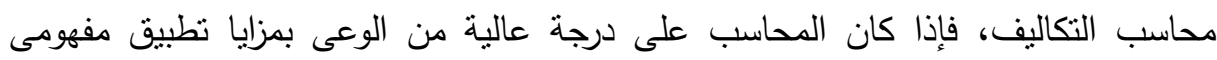

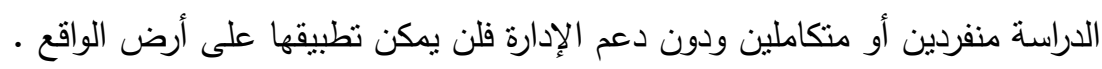

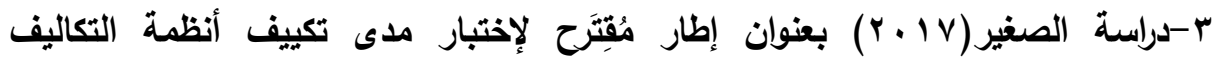

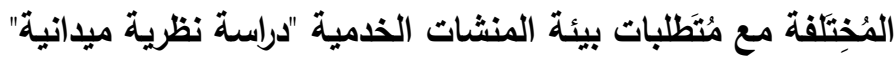

تحدثت هذه الدراسة عن أهمية وضع خطة مستهدفة للتكلفة قبل البدء فى الإنتاج، وفى دئه

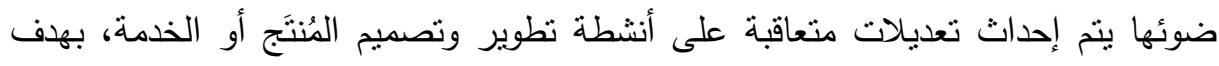

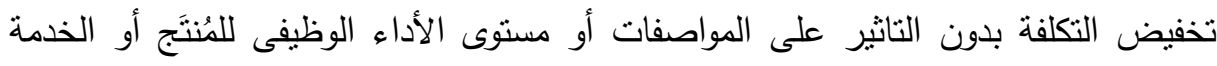

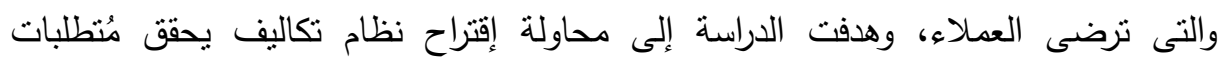

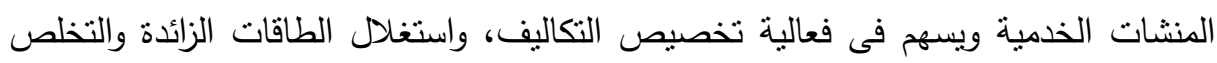
من الفاقد، وخلصت الاراسة إلى أن نظام استهلاك الموارد يقدم نظرة مستقبلية لإستهلاك

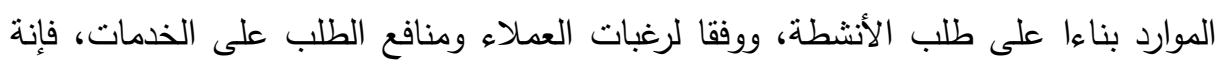

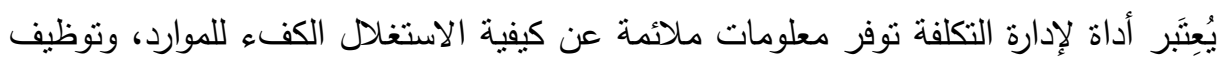
الطاقات العاطلة بما بساعد على خفض التكلفة.

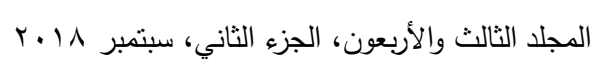


ثانياً: دراسات باللغة الانجليزية:

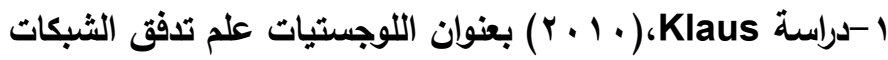
تهرف هذه الدراسة إلى تحديد طبيعة اللوجستيك والهدف من تطبيق اللوجستيك، حيث كانت مشكلة البحث فى كيفية النطبيق العملي للوجستيك في الاقتصاد وتحسين العمليات

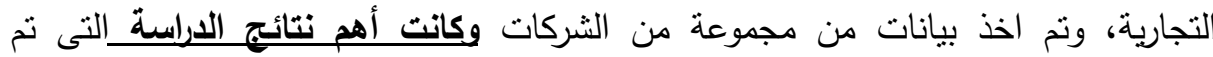
التوصل إليها، أن اللوجستيك هو تطبيق علمي يقوم على أساس عمل نماذج وتحليل للنظم الاقتصادية وتدفق البضائع والمعلومات والمال والأفراد، عبر الزمان والمكان مما يخلق قيمة لهونة لوجستية لاى الأفراد، كما تهدف إلى التقدم في تحقيق اقتصاد منوازن يحافظ على البيئة

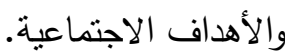

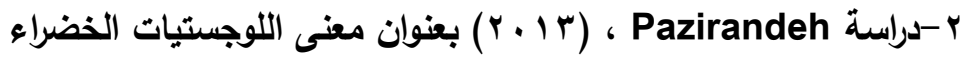
الغزض من هذه الدراسة هو تقييم الجهود المبذولة للوصول للوجستيات الخضراء، وهل تؤثر هذه الجهود على كفاءة وفعالية اللوجستيات بصفة عامة، ماهى العلاقة بين استخدام الانشطة اللوجستية الخضراء وتحسن الاداء اللوجستيى نتيجة لذلك، وعرضت الدراسة لضرورة اتخاذ القرارات التى تؤدى إلى تقليل الإنبعاثات الناتجة عن عملية النقل، بإعتبار أن النقل هو واءه أكبر مصادر الخطر البيئى فى النظام اللوجسنيى، وخلُصت الدراسة إلى أن اكثر العناصر خطورة على البيئة فى النظام اللوجستيى هو النقل ويجب أن نُرَكَز على هذا العنصر حتى النى

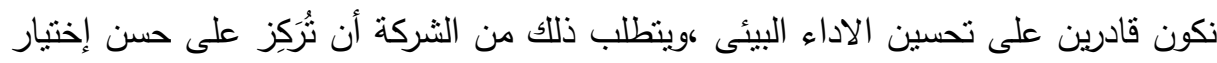

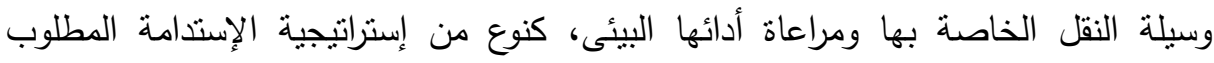
توافرها بالثركة بما يؤدى إلى الكفاءة والفعالية فى اداء الخدمة.

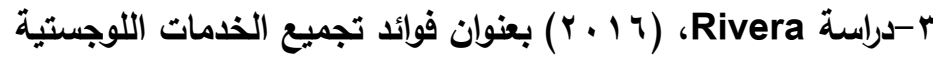

عرضت هذه الدراسة فوائد التجمعات الصناعية اللوجستية بين الثركات منل الوصول

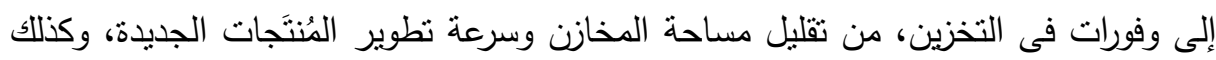

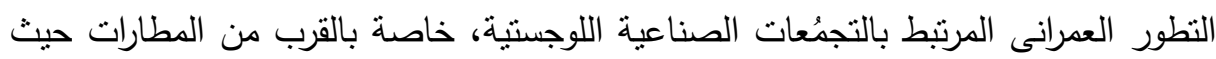

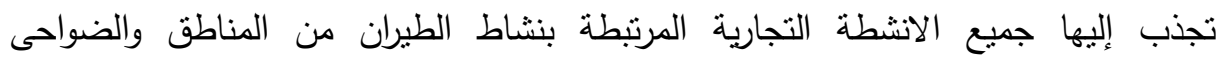


المختلفة، ويشمل ذلك الثركات والفنادق ومكاتب شركات الطيران والثحن الجوى، وخلُصت اللاراسة إلى أن تجميع الخدمات اللوجستية يوفر العديد من المزايا الرئيسية للشركات، وتقديم

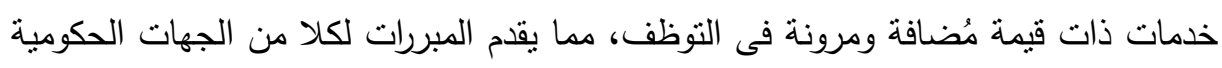
والجهات الخاصة للإستثمار فى هذا المجال.

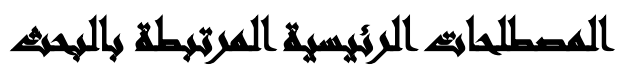

1 - اللوجستيات: يشير مصطلح اللوجستيات إلى أسلوب إدارة تدفق السلع والخدمات التى تحتاج إليها المنشأة ونظام المعلومات اللازم لتحقيق هذا التدفق. وتتلاشى أهمية وظيفة

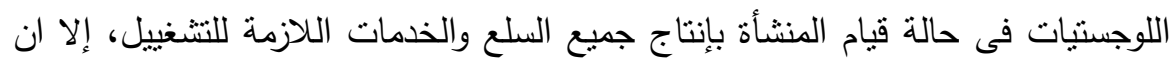

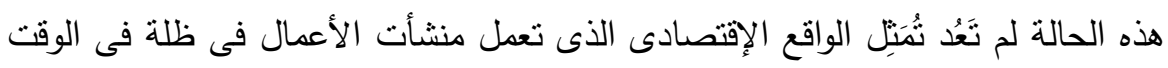

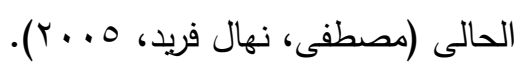

r بلسلة القيمة: هى وسيلة لتحقيق الإدارة الاستراتيجية للتكاليف، أوادارة التكاليف

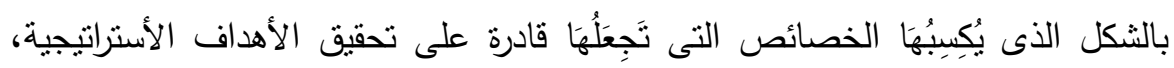

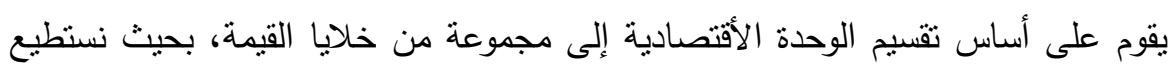

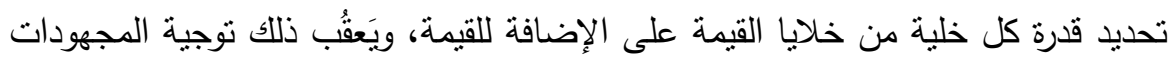

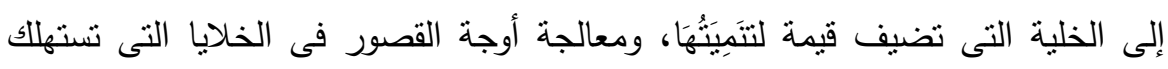

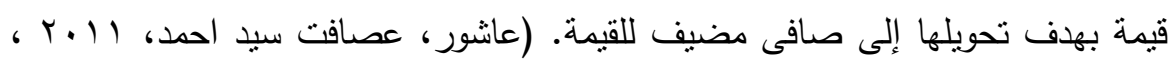

r- تكاليف اللوجستيات: يُقِصد بتكلفة اللوجستيات هى مجموعة التكاليف التى يتم إنفاقها

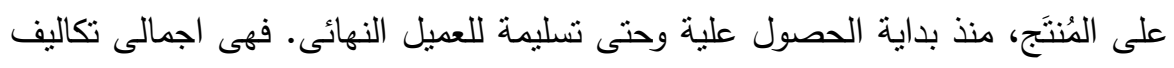
شبكة الخدمات اللوجستية بالثركة ، و بدأ الإهنمام بموضوع التكاليف اللوجستية وإدارتها

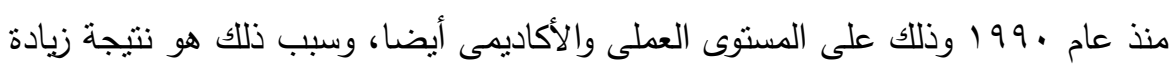

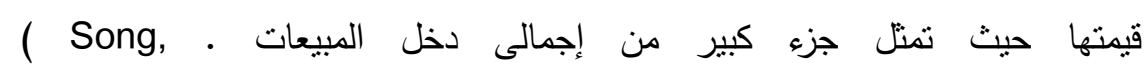
Hua\&Wang,Lan,2009,p659) 


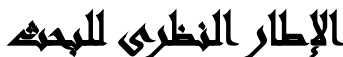

يتتاول هذا الجزء بالعرض والتحليل الجوانب المُرتبطة بموضوع الدراسة وهى إستخدام سلسلة القيمة لتخفيض تكاليف اللوجستيات فى مجال الثحن الجوى،حيث تعثبر من أكثر الإستراتيجيات والمعايير التي أثنتت فاعليتها في مجال تخفيض التكلفة ورفع الميزة التتافسية وهى سلسلة القيمة لمايكل بورتز، وسيتم تتاول هذه الجوانب بقليل من التفصيل فى الجزء

ا-سلاسل القيمة فى الشحن الجوى: سلسلة القيمة هي أسلوب منهجي يهدف إلى تطوير المزايا التي تجعل المُنتجج على قدر عالي من التتافسية وذلك بان تغطى كل العمليات التي يمر بها المُنتَج بدأ من عملية التصميم وإنتهاء بالتوزيع والهدف من الأنشطة

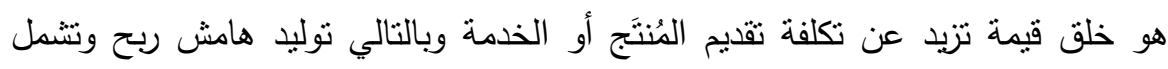

$$
\text { العمليات التي يمر بها المُنتنَج }
$$

-الخدمات اللوجستية الواردة وتتشمل الإستلام والتخزين ومراقبة المواد الخام المُخَزَنة

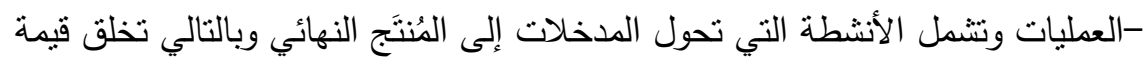

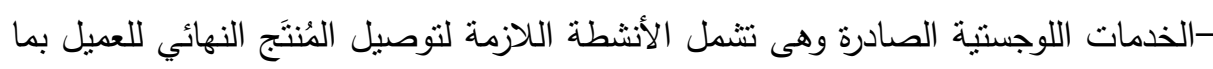
في ذلك النقل والتخزين -التسويق والمبيعات وهى الأنشطة الخاصة بكيفية الوصول للمشتريين الذين يقومون بشراء المُنتَج النهائي بما في ذلك من أنشطة الإعلانات والتسعير . r-تكاليف اللوجستيات: تُعرف للوجستيات بانها هى الأنشطة الداعمة للعملية الإنتاجية،

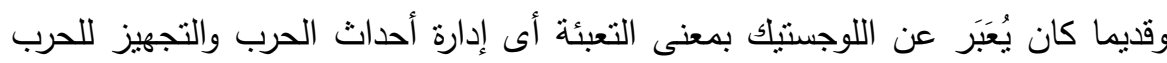

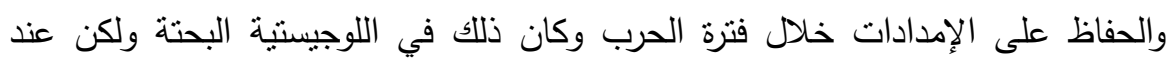
الحديث عن اللوجستيك في مجال العمل فقد تغير مفهوم اللوجستيك وأصبح توجه اللوجستيك في المقام الأول في تحسين العمليات التجارية وزيادة فعالية الاقتصاد

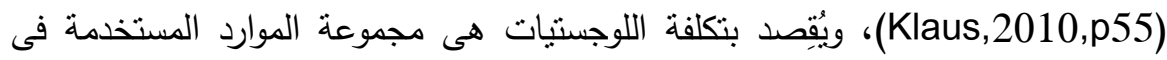
إنتاج سلعة او اداء خدمة او اقتتاء اصل وذلك حتى وصولة للعميل النهائى او مستقبل 
الخدمة، وبدأ الإهنمام بموضوع التكاليف اللوجسنية وإدارتها منذ عام .99 (،وفى ظل المناخ الأقتصادي السريع السائد الآن فإن كثثر من الثركات تدرك بصورة أكبر أن أن الندان

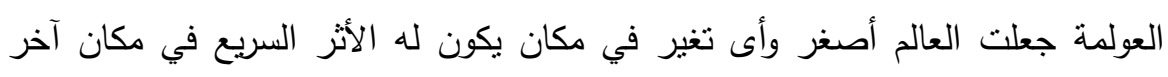

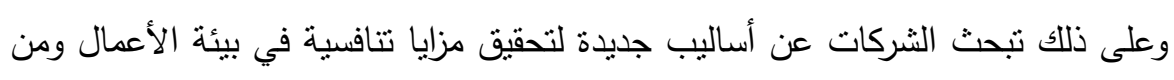
أحدى هذه المزايا التتافية للشركات هو تعزيز وخفض التكلفة للعملاء من خلال إستخدام

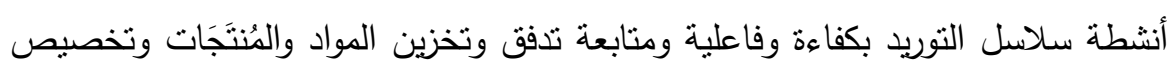
المعلومات لسلاسل التوريد لتلبية الطلب وتحقيق رضاء العملاء فإدارة الآثار اللوجسنية تمنحنا مصدر كبير من المزايا التتافية وذلك لو أمكننا التحكم في التكلفة وتعزيز التمايز في الخدمة وهذا الدور الفريد سوف يساعد الثركات لتصبح لها الريادة في التكلفة والقيمة وبالتالي يزيد الإعتراف بالإدارة اللوجيسنية الجيدة وذلك لدَعَدُها وهى التي تساعد الثركة

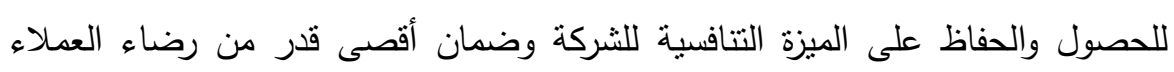

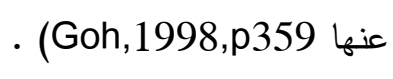

بل يعتمد الأداء العالي للمنظمة على القدرة التصنيعية لهذه المنظمة لتصبح شريك

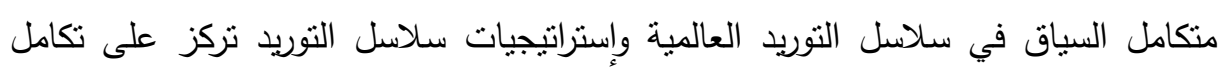
العمليات التجارية الداخلية والخارجية وذلك من أجل خدمة أفضل للعملاء وكمثال للخدمات

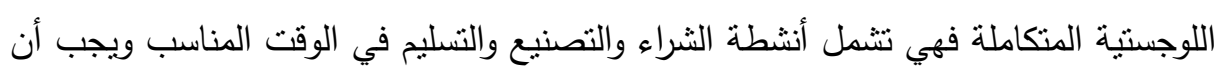

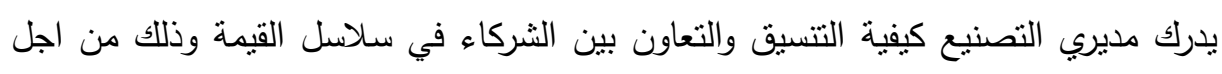
دعم المنافسة لسلاسل التوريد (318- (Green,2008,pp 317). ب-اللوجستيات الخضراء: وتُعَرف اللوجسنيات الخضراء بأنها الأنشطة الداعمة للعملية

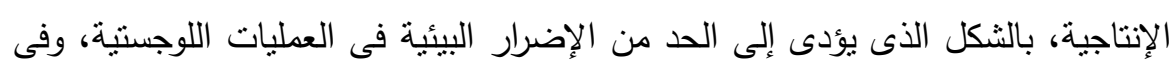

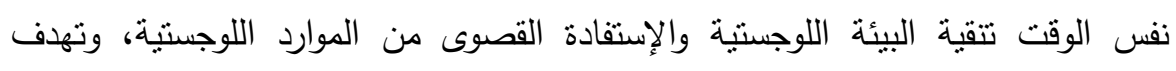

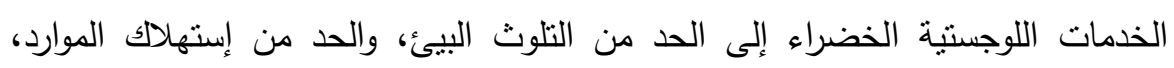
بإستخدام التكنولوجيا اللوجستية المتقدمة فى التخطيط، وتتفيذ النقل والتخزين والتعبئة والتحميل والتقريغ، وتجهيز دورة العمل وغيرها من الإنشطة اللوجسنية.

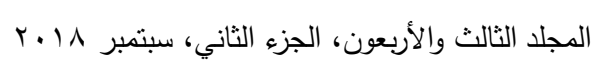


الحديث عن اللوجستيات الخضراء او لوجستيات المسئولية البيئية، وعرض للتكاليف اللوجستية، عناصرها، التكاليف البيئية ومكوناتها،والوصول الى إقتصاديات الثحن الجوى

ودراسة الحالة بتطبيق نموذج سلاسل القيمة للوسول للنتائج والتوصيات الخاصة بالدراسة. ع -النموذج المقترح كطبيقة: يعتمد النموذج المقترح فى إعدادة إلى البيانات التى نم الحصول عليها من الثركة موضع الدراسة، والتى تخص فترتين زمنيتين متتاليتين والتى امكن من خلالها إعداد خلايا سلاسل القيمة لانشطة الثركة، وتم المقابلة بين تكلفة كل خلية وسعر بيع الوحدة وهو وفق اسعار المنافسين فى السوق، بهدف تحديد قدرة كل خلية على الإضافة للقيمة من عدمة،ومن ثما توجية النظر للخلايا المستهلكة للقيمة للتحول بها إلى ان تكون مضيفة للقيمة،وتحقيق الهدف الرئيسى للبحث وهو تخفيض تكاليف اللوجستيات،حيث تقوم الثركة موضع الدراسة بتقديم خدمة الثحن الجوى للسلع والمنتجات سواء تامة الصنع او الخامات وقطع الغيار، فاساس عمل الثركة هو تقديم خدمة لوجسنية تهدف إلى توصيل السلع والمنتجات للوجهة النهائية، فى الوقت والمكان المناسب وبتكلفة اقل من المنافسين وبجودة مرتفعة،وهذا هو جوهر عمل اللوجستيات والخاص بجميع الأنشطة الداعمة للعملية الأنتاجية، بدءا من الحصول على المادة الخام وحتى توصيل المُنتَج للعميل النهائى،وفى سبيل ذللك فهناك تكاليف يتم تحملها والهدف الذى نسعى إلية من خلال هذا النموذج هو تخفيض تلاك التكلفة. ولقد كثف تحليل خلايا سلسلة القيمة للشركة (س) عن وجود خلايا مستهلكة للقيمة

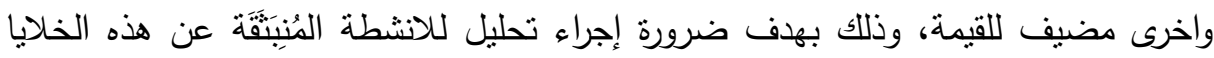

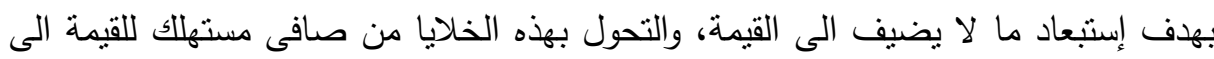
صافى مُنتِج للقيمة. 


\section{الإجباءايت المنهجية}

1-منهج الاراسة: يشمل منهج الدراسة الآتي: - المنهج الاستقرائى: حيث أعتمد الباحث على مزيج من البهائ البيانات المرجعية بإستخدام المنهج

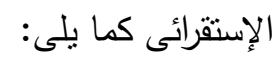

-بعض المراجع العلمية التى تناولت موضوع سلسلة القيمة ودورها فى تخفيض تكاليف

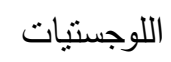

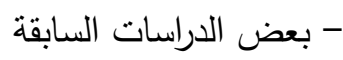

- المنهج الاستنباطى: ينم إستخدام هذا الدنهج من خلال النطبيق على شركة (س) للثحن

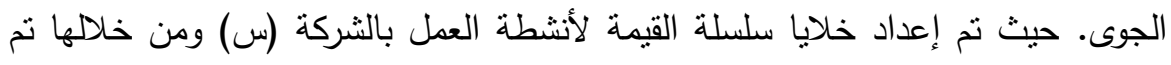
تحديد الخلايا التى تعتبر مضيفة للقيمة والخلايا المستهلكة للقيمة.

$$
\text { ب-أدوات الداسة وطرق البحث: }
$$

ا- طرق البحث: تقتصر الدراسة على تحليل العلاقة بين سلاسل القيمة والنكاليف اللوجستية

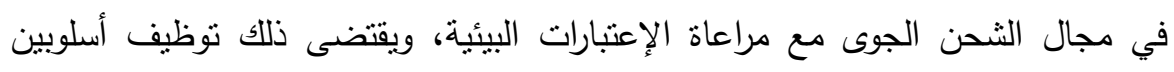

$$
\text { لأغراض تحقيق الأهداف البحتية،هما: }
$$

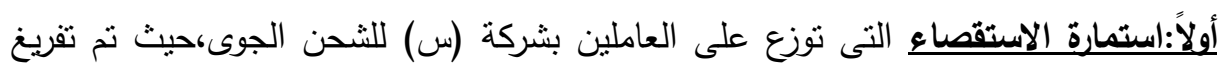

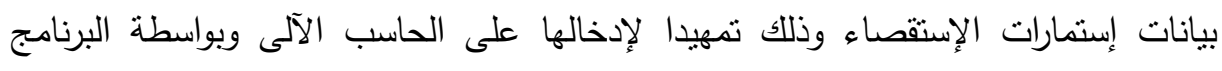

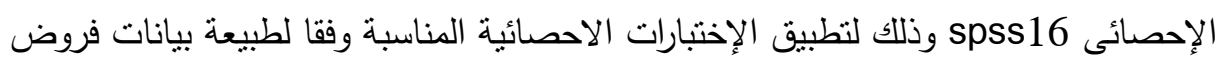

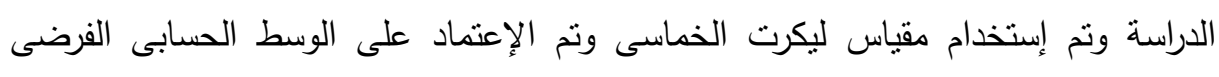

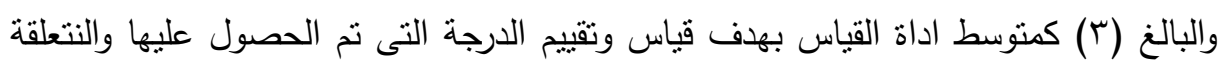
بإستجابات افراد عينة الدراسة.. ثانياً: نتائج إختبارات الصدق والثبات الثبات لإستمارة الإستقصاء:

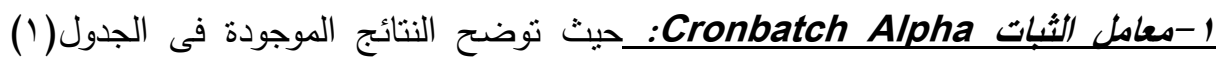

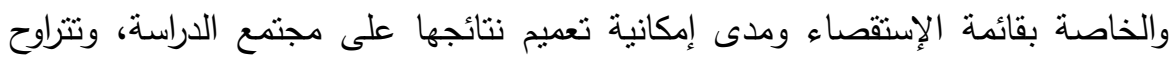

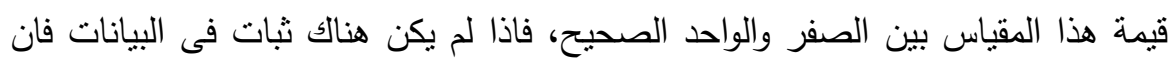

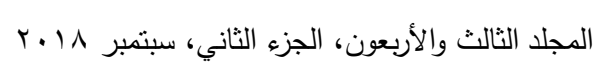


قيمة هذا المعامل تساوى صفر، وعلى العكس اذا كان هناك ثبات تام فى البيانات فان

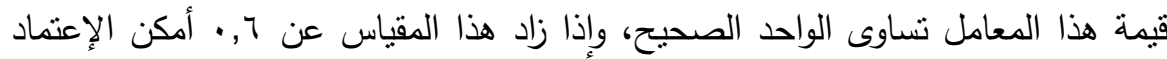

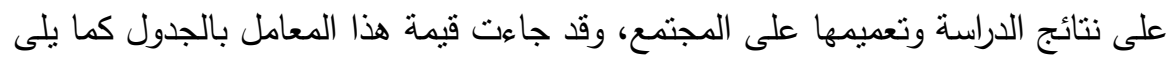

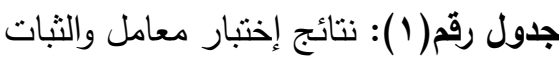

\begin{tabular}{|c|c|c|c|}
\hline $\begin{array}{l}\text { معامل الثُبات } \\
\text { (Alpha) }\end{array}$ & العناصر & البيان & الفرض \\
\hline$\cdot, T \vee \wedge$ & 7 & طبيعة العلاقة بين تطبيق سلسلة القيمة وتخفيض اللوجستية & الأول \\
\hline$\cdot, \wedge) \wedge$ & $\mathrm{v}$ & العلاقة بين إستخداد الحركة التجارية القيمة وزيشركة آرباح & الثانى \\
\hline$\cdot, \mathrm{V} \sim \mathrm{V}$ & 7 & الإرتباط بين إستخدام سلسلة القيمة وتخفضض الفاقد & الثالث \\
\hline$\cdot, \wedge \wedge r$ & 7 & العلاقة بين إستخدام اللوجستيات لسلسلة القيمة & الرابع \\
\hline$\cdot, V Y)$ & ro & 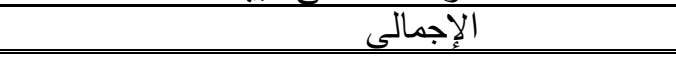 & \\
\hline
\end{tabular}

وتتثير نتائج إختبار معامل الثبات كما فى الجدول (1) ان قيمة معامل الفاكرونباخ لإستمارة الإستقصاء (VYI, (·) للثبات وهى معامل مرتفع ويمكن الإعنماد على نتائج الدراسة وتعميمها على المجتمع ץ-معامل الصدق: تشبر نتائج إختبار معامل الصدق والموجودة فى جدول (ץ)،(؟) أن قيم معامل الصدق مقبولة لجميع فروض الدراسة، حيث تضمنت قائمة الإستقصاء على اربعة اقسام كل قسم يتضمن مجموعة من العناصر والاسئلة ويتم حساب معامل الصدق لبحث مدى صدق المستقصى منهم، وذللك بتكرار الإختبار على مجموعة اخرى، او بتكرار الاسئلة داخل نفس الإختبار بصيغة مختلفة ومراجعة هل هناك صدق فى إجابات المستقصى منهم أم لا، وينم حساب معامل الصدق لبحث مدى الإعتماد على نتائج الدراسة الميدانية فى تعميم النتائج 
جدول رقم(ץ): نتائج إختبار معامل الصدق

\begin{tabular}{|c|c|c|c|}
\hline الصدامل & العناصر & 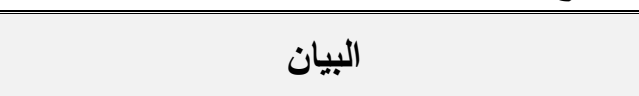 & 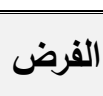 \\
\hline$\cdot, \lambda r \varepsilon$ & 7 & طبيعة العلاقة بين تطبيق سلسلة القيمة وتخفيض اللتبنة & 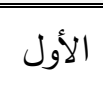 \\
\hline$\cdot, 9 \cdot \varepsilon$ & $V$ & العلاقة بين استخداد الحركة التجارية بالثية وزيادة أرباح & الثانى \\
\hline$\cdot, \wedge \circ \wedge$ & 7 & الإرتباط بين استخدام سلسلة القيمة وتخفسض اللوجستيات & 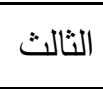 \\
\hline$\cdot, 949$ & 7 & العلاقة بين استخدام اللوجستيات لسلسلة القيمة & الرابع \\
\hline$\cdot, \wedge 01$ & ro & الإجمالى & \\
\hline
\end{tabular}

وطبقا لهذا الإختبار كلما اقتربت قيمة الفا من الواحد الصحيح دل ذلك على المصداقية

وعلى العكس كلما اقتربت قيمة الفا من الصفر دل ذللك على عدم المصداقية ومن واقع

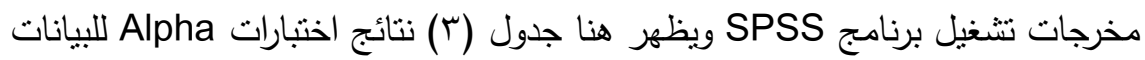
جدول رقم(r): نتيجة إختبارات Alpha للبيانات

\begin{tabular}{|c|c|c|}
\hline Prob & F & Alpha \\
\hline \hline,$\cdots$ & $1 \Sigma, \wedge Y Y$ &,,$\wedge 01$ \\
\hline
\end{tabular}

وتظهر لنا قيمة الفا (101, •) وهى تدل على ان هناك علاقة جوهرية عند مستوى

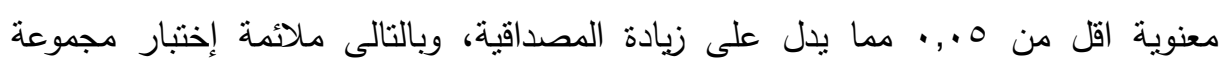
متغيرات الدراسة

ثالثا: تحليل وإختبارات علاقات الإتباط بين متغيرات الدراسة: تركز هذه الفقرة على قياس

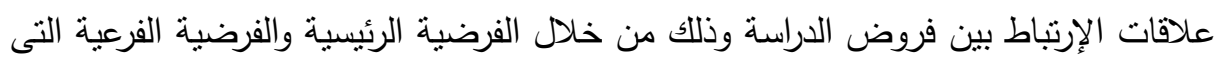
تضمنتها الدراسة ونم إستخدام معامل الارتباط البسيط (بيرسون) وإستخدام إختبار (T) لإختبار

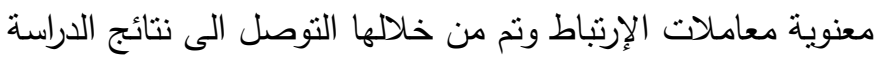
رايعا: استخدام أسلوب تحليل سلسلة القيمة وذلك للتحول بتكاليف خلايا القيمة التى لم لم تكتسب المقدرة الأستراتيجية إلى تكاليف استراتيجية حيث تَوَفَرَت لدى الباحث التكاليف الخاصة ببعض أنشطة الشركة(س) وذلك على مدى فترتين زمنيتين متتاليتين، ومن خلال

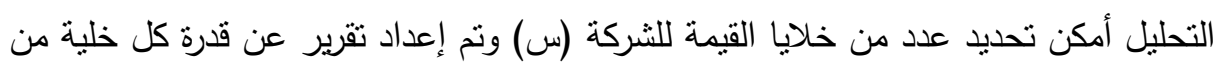
خلايا القيمة على الإضافة للقيمة وذلك خلال الفترتين الزمنيتين

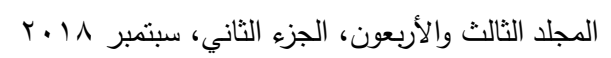


ج-العينة وتوصيفها وحجم العينة: تم إختبار عينة البحث بحيث تكون ممثلة لمجتمع الدراسة، وتم تحديد حجم العينة Yq مفردة نم إختبارها من العاملين بالثركة (س) للثحن الجوى وروعى فى إختبار عناصرها ان تمثل جميع أطياف مجتمع الدراسة. د-متى واين اجريت الدراسة: نم إختيار احدى شركات الطيران كنموذج لتطبيق فروض

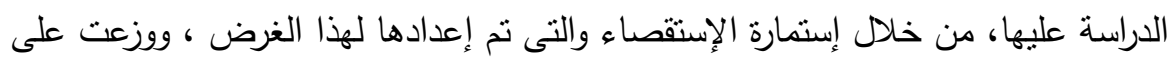

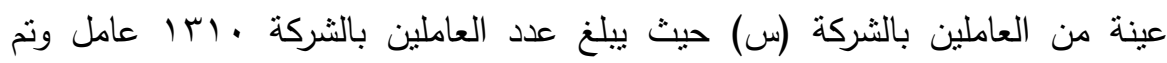

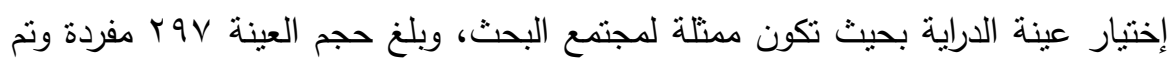

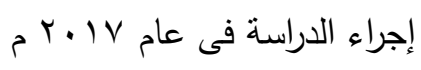

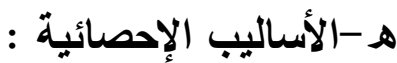

أولاً: تجميع بيانات إستمارات الإستقصاء وتحليلها ودراسة علاقات الإرتباط بين تطبيق سلاسل

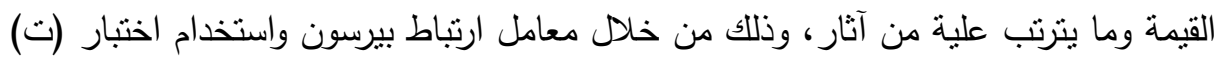
لقياس معنوية معاملات الإرتباط، ونم التوصل للنتائج التالية: 1-اتضح وجود علاقة ارتباط موجبة ذات دلالة إحصائية معنوية بين مبدا نطبيق سلسلة

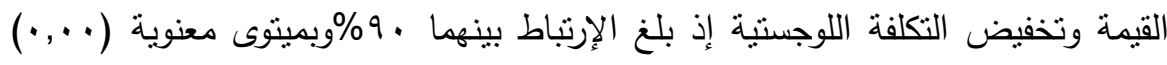
وهى اقل من ا ..., · وهذا يدل على وجود علاقة إرتباط طردية بين فروض الدراسة. r-وللتحقق من الفرضية الفرعية الثانية وجد أن هنالك علاقة إرتباط موجبة ذات دلالة إلة إحصائية معنوية بين مبدا تطبيق سلاسل القيمة وزيادة أرباح الشركة اذ بلغ الإرتباط بينها

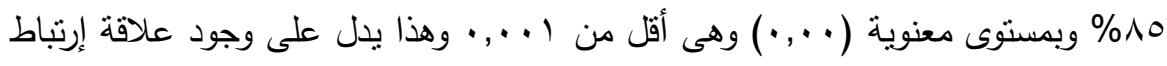

$$
\text { طردية بين فروض الدراسةز }
$$

r-للتحقق من صحة الفرضية الثالثة اتضح وجود علاقة ارتباط موجبة ذات دلالة احصائية معنوية بين مبدا تطبيق سلاسل القيمة وتخفيض الفاقد فى اللوجنتيات اذ بلغ الإرتباط

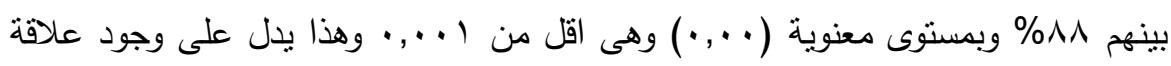
إرتباط طردية بين فروض الدراسة. 
ثانيا:استخدام أسلوب تحليل سلسلة القيمة: وقد أمكن وفقا للإطار الفكرى ومن خلال الدراسة النظرية تحديد خمس خلايا للقيمة هى 1- (خلية نشاط الطائرات،

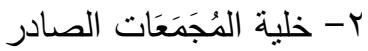

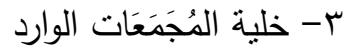

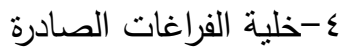
0-خلية الفراغات الوارد

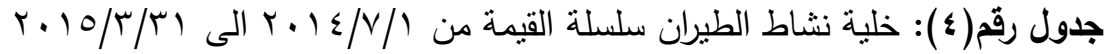

\begin{tabular}{|c|c|c|c|}
\hline جم/ساعة & \multicolumn{2}{|c|}{ التكاليف وعدد الوحدات } & \\
\hline \multirow[t]{11}{*}{$510 \ldots$} & & & سعر بيع ساعة الطيران \\
\hline & & & التكاليف \\
\hline & $r .1911 \%$ & & الاجور \\
\hline & $1 . \Sigma \varepsilon Y \mid Y T Y$ & & المستلزمات السلعية \\
\hline & & TETIAYAT & مصروفات \\
\hline & & T077 $\leqslant \leqslant 70$ & مصروفات تحويليلة جارية \\
\hline & & VOYAVqYq & مصروفات خدمية اخرى \\
\hline & $1 \leqslant 07 V .7 \mathrm{VV}$ & & اجمالى المصروفات \\
\hline & $r \cdot \Lambda \wedge T \leq \varepsilon$ & & اجمالى الاعباء والخسائروتعويضات \\
\hline & YA7/997VI & & اجمالى التكاليف(|) \\
\hline & rol 1 & & عدد ساعات الطيران (ب) \\
\hline A) $\leqslant \leqslant 0$ & & & تكلفة الوحدقبالساعة (ا/ب) \\
\hline$(99 \leqslant 0)$ & & & الاضافة للقيمة \\
\hline
\end{tabular}

الجدول السابق رقم(ع) يمنل اولى خلايا القيمة فى الشركة محل الدراسة ومن خلاله نجد ان هذه الخلية(خلية نشاط الطيران) تعنبر مستهلكة للقيمة وذلك لأن إجمالى نكاليف هذهابه الخلية اكبر من سعر بيع الوحدة وذلك وفق اسعار المنافسين فى السوق حيث تعنتر هذه

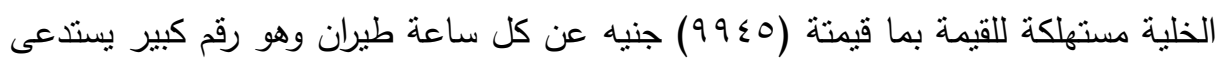
معة تحليل الانثطة المنبثقة عن هذه الخلية وذلك بهدف إستبعاد ما لا يضيف منها إلى القيمة

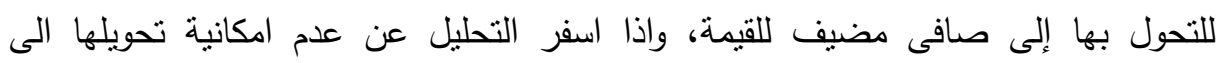
مضيف للقيمة فيكون القرار هو باستبعاد هذه الخلية لأنها تؤثر بالسلب على الثركة ككل. 
مجلة العلوم البيئية

معهد الدراسات والبحوث البيئية - جامعة عين شمس لبهن

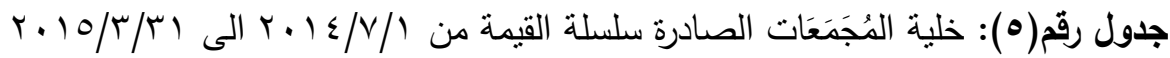

\begin{tabular}{|c|c|c|c|}
\hline جم/ساعة & \multicolumn{2}{|c|}{ التكاليف وعدد الوحدات } & \\
\hline \multirow{10}{*}{ ITKI } & & & سعر البيع لخدمة طن البضائع الصادرة \\
\hline & & & التكاليف \\
\hline & $19.01 Y V \varepsilon$ & & الاجور \\
\hline & $r Y \cdot \Lambda \ldots r$ & & مستلزمات سلعية \\
\hline & & 1001 ATY & مصروفات \\
\hline & & TVEYTOO & مصروفات خدمية اخرى \\
\hline & $0 Y q \leq \cdot \Lambda V$ & & اجمالى المصروفات \\
\hline & $1 \leqslant r$ & & اجمالي الاعباء والخسائروتعويضات \\
\hline & Y707IVAr & & اجمالي التكاليف (|) \\
\hline & Iron. & & وزن البضائع الصادرة بالطن (ب) \\
\hline 1900 & & & تكلفة الوحدة لكل طن (ا/ب) \\
\hline$(V r \varepsilon)$ & & & الاضافة للقيمة \\
\hline
\end{tabular}

الجدول السابق رقم(0) يمثل ثانى خلايا القيمة فى الثركة محل الدراسة ومن خلاله نجد

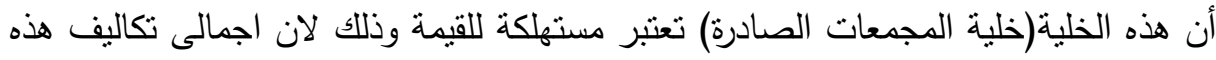

الخلية اكبر من سعر بيع الوحدة وذلك وفق أسعار المنافسين فى السوق حيث تعتبر هذه

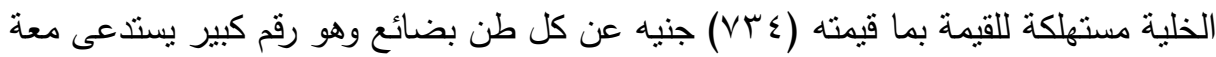

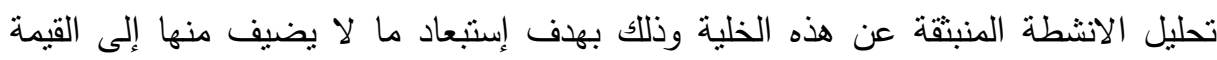

للتحول بها إلى صافى مضيف للقيمة

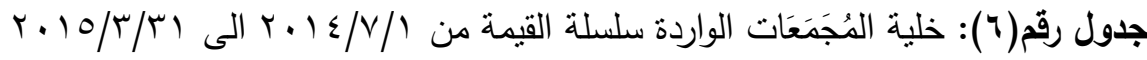

\begin{tabular}{|c|c|c|c|}
\hline جم/ساعة & \multicolumn{2}{|c|}{ التكاليف وعدد الوحدات } & \\
\hline $11 \leqslant r$ & & & سعر البيع لخدمة طن البضائع الواردة \\
\hline & & & التكاليف \\
\hline & 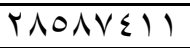 & & الاجور \\
\hline & (ז... & & مستلزمات سلعبة \\
\hline & & TrYVVEV & مصروفات \\
\hline & & OTITMN & مصروفات خدمية اخرى \\
\hline & Vqsוाए. & & اجمالي المصروفات \\
\hline & $r \mid M$ & & اجمالي الاعباء والخسائروتعويضات \\
\hline & 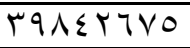 & & اجمالي التكالبف(|) \\
\hline & 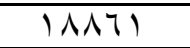 & & وزن البضائع الواردة بالطن (ب) \\
\hline$r \| r$ & & & تكلفة الوحدة لكل طن (ا/ب) \\
\hline$(979)$ & & & الاضافة للقيمة \\
\hline
\end{tabular}


الجدول السابق رقم(7) يمنل ثالث خلايا القيمة فى الثركة محل الدراسة ومن خلالة نجد

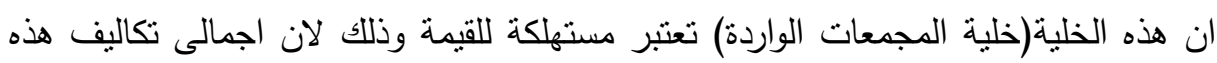
الخلية اكبر من سعر بيع الوحدة وذلك وفق اسعار المنافسين فى السوق حيث تعتبر هذه

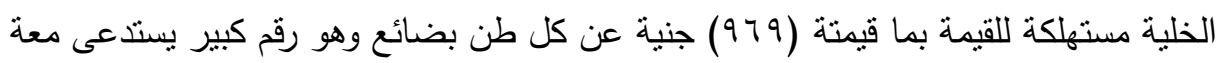
تحليل الانشطة المنبتقة عن هذه الخلية وذلك بهدف إستبعاد ما لا يضيف منها إلى القيمة للتحول بها إلى صافى مضيف للقيمة

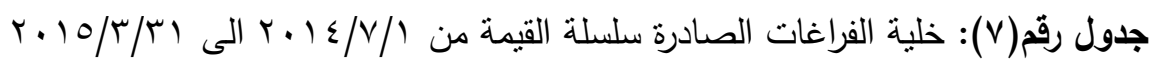

\begin{tabular}{|c|c|c|c|}
\hline جم/ساعة & \multicolumn{2}{|c|}{ التكاليف وعدد الوحدات } & \\
\hline TI & & & سعر البيع لخدمة طن الفراغات للبضائع الصادرة \\
\hline & & & التكاليف \\
\hline & Y97ะ7ाT & & الاجور \\
\hline & r91997 & & مستلزمات سلعية \\
\hline & & r... & مصروفات \\
\hline & & $\varepsilon 09 \wedge \varepsilon 1$ & مصروفات خدمية اخرى \\
\hline & 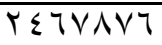 & & اجمالى المصروفات \\
\hline & $177919 \varepsilon$ & & اجمالى الاعباء والخسائروتعويضات \\
\hline & $V) \leqslant Y r V q$ & & اجمالى التكاليف (|) \\
\hline & 01891 & & وزن البضائع الصادرة بالطن (ب) \\
\hline $1 \mu \mathrm{V}$ & & & تكلفة الوحدة لكل طن (ا/ب) \\
\hline $1 \cdot \Lambda \varepsilon$ & & & الاضافة للقيمة \\
\hline
\end{tabular}

الجدول السابق رقم(V) يمثل رابع خلايا القيمة فى الثركة محل الدراسة ومن خلالة نجد

ان هذه الخلية(خلية الفراغات الصادرة) تعتبر صافى مضيف للقيمة وذللك لان اجمالى تكاليف هذه الخلية اقل من سعر بيع الوحدة وذلك وفق اسعار المنافسين فى السوق حيث تعتبر هذه هذه الخلية مضيفة للقيمة بما قيمتة ؟1 ـ 1 جنية عن كل طن وذلك يعنى العمل ايضا على تقييم

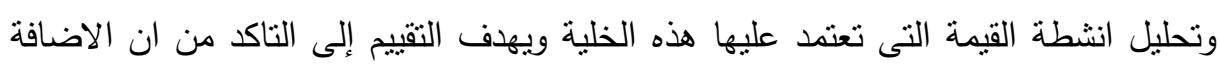

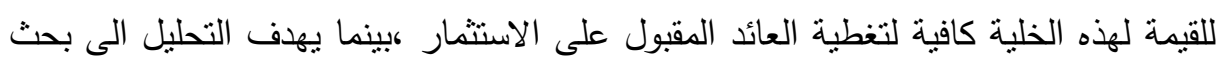

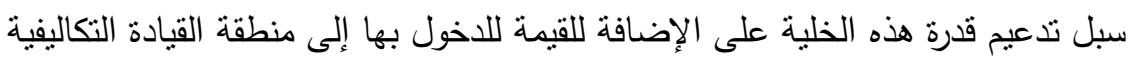


مجلة العلوم البيئية

معهد الدراسات والبحوث البيئية - جامعة عين شمس لينه

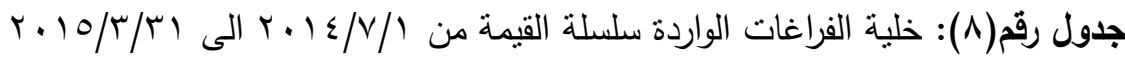

\begin{tabular}{|c|c|c|c|}
\hline 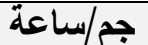 & \multicolumn{2}{|c|}{ التكاليف وعدد الوحدات } & \\
\hline IYTI & & & سعر البيع لخدمة طن الفراغات للبضائع الواردة \\
\hline & & & التكاليف \\
\hline & $\varepsilon \varepsilon \varepsilon 79 Y$. & & الاجور \\
\hline & $09 \wedge \leqslant 7$ & & مستلزمات سلعية \\
\hline & & $r .1 Y .01$ & مصروفات \\
\hline & & $7199 \vee 74$ & مصروفات خدمية اخرى \\
\hline & MV.INIT & & اجمالى المصروفات \\
\hline & 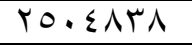 & & اجمالي الاعباء والخسائروتتعويضات \\
\hline & I.VITEIV & & اجمالي التكاليف(|) \\
\hline & $\varepsilon Y \vee \leqslant \Lambda$ & & وزن البضائع الصادرة بالطن (ب) \\
\hline TO. & & & تكلفة الوحدة لكل طن (ا/ب) \\
\hline 971 & & & الاضافة للقيمة \\
\hline
\end{tabular}

الجدول السابق رقم(^) يمثل خامس خلايا القيمة فى الثركة محل الدراسة ومن خلالة

نجد ان هذه الخلية(خلية الفراغات الواردة) تعتبر صافى مضيف للقيمة وذلك لان اجمالى تكاليف هذه الخلية اقل من سعر بيع الوحدة وذلك وفق اسعار المنافسين فى السوق حيث تعنبر هذه الخلية مضيفة للقيمة بما قيمتة اج9 جنية عن كل طن وذلك يعنى العمل ايضا على تقييم وتحليل انشطة القيمة التى تعتمد عليها هذه الخلية ويهدف التقييم إلى التاكد من ان الاضافة للقيمة لهذه الخلية كافية لتغطية العائد المقبول على الاستنمار ،بينما يهدف التحليل الى بحث سبل تدعيم قدرة هذه الخلية على الإضافة للقيمة للاخول بها إلى منطقة القيادة

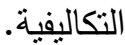

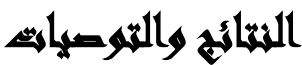

أولاً: التتائجج: - (1)

1-كثف تحليل خلايا سلسلة القيمة للشركة (س) عن وجود خلايا مستهكة للقيمة وأخرى مضيف للقيمة، وذلك بهذف ضرورة إجراء تحليل للانشطة المُنْبَتَََّة عن هذه الخلايا بهدف

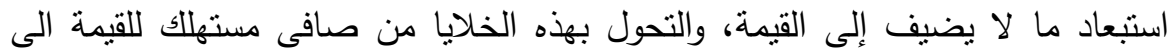
صافى مُنتِج للقيمة. 
r-تمتل الخلايا المضيفة للقيمة فى خلية الفراغات الصادرة(جدول 0) وخلية الفراغات

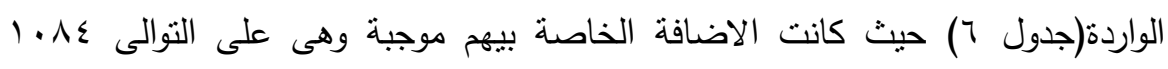

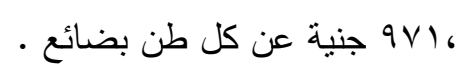

r- من خلال الدراسة السابقة وجد ايضا ان هناك خلايا مستهلكة للقيمة وتمثلت ثلك الخلايا

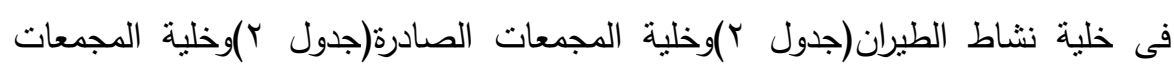

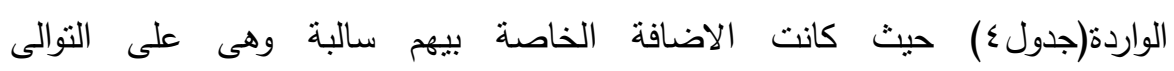

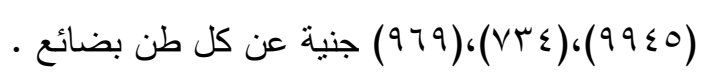

ع بالنسبة للخلايا المُستَهكة للقيمة يتطلب الأمر تحليل أنشطة القيمة لهذه عنه الخلايا بهدف

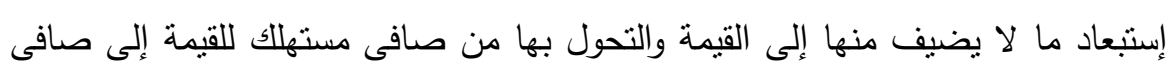
منتج للقيمة إذ أن كفاءة هذه الخلايا فى إستهلاك الموارد فى حالة تدهور وهنا يكون القرار

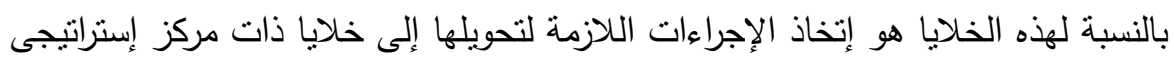

$$
\text { ثانياً: التوصيات إستبعادها . }
$$

اسيوصى الباحث بضرورة تطبيق نموذج سلسلة القيمة على اعمال الثركة، لما له من آثار

$$
\text { إيجابية على الثركة. }
$$

ب-نينغى الاهتمام بموضوع اللوجستيات الخضراء،لما لها من آثار إيجابية على البيئة المحيطة

$$
\text { وعلى المجتمع ككل. }
$$

ب-يقترح الباحث ضرورة توافر قاعدة من البيانات فى الثركات، وذللك لإمكانية تطبيق النموذج

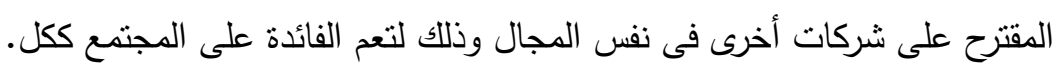

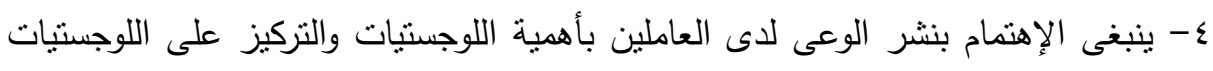
الخضراء،كاحدى الوسائل لتحقيق منطلبات التتمية المستدامة على مستوى الثركة. ه-يقترح الباحث تدريب المحاسبين ومعدي المعلومات المالية وغير المالية على استخدام نموذج سلاسل القيمة لما للة من فائدة فى تخفيض التكلفة وتحديد الخلية التى بها قصور

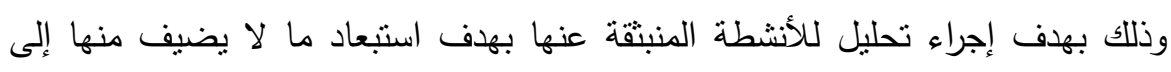
القيمة والتحول بهذه الخلايا من صافى مستهلك للقيمة إلى صافى منتج للقيمة .

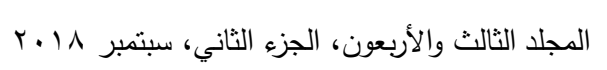




\section{المرالئي}

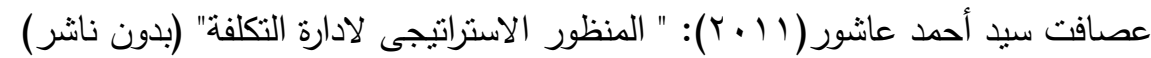

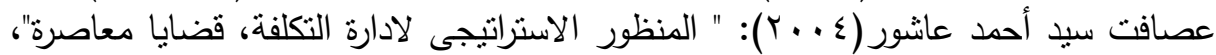
(بدون ناشر عانشور)

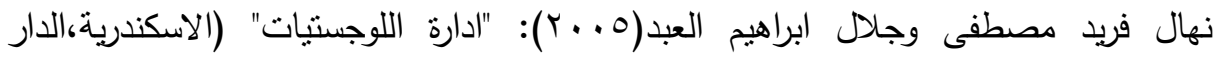

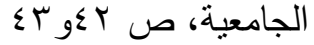

محمد السيد محمد الصغير : "اطار مقترح لاختبار مدى تكيف انظمة التكاليف المختلفة مع الفية

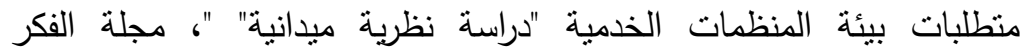
المحاسبى، كلية التجارة، جامعة عين شمس، العدد الثانى، الجزء الثانى، لنّات r. IV

حنان محمد مسطفى درويش: "اطار مقترح لقياس اتجاهات محاسب التكاليف نحو اثر العلاقة

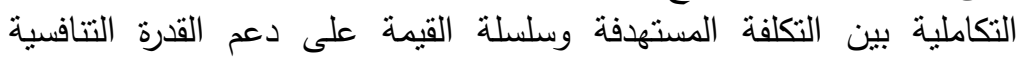

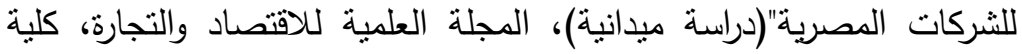

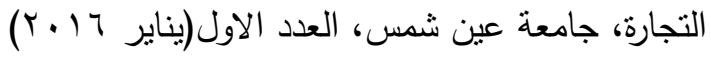

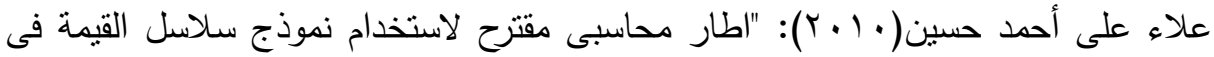

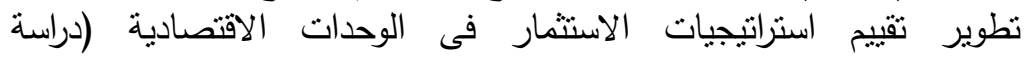
تطبيقية)"رسالة دكتوراة غير منشورة، كلية التجارة، جامعة عين شمس التش

Kaplan,Athinson,Young"management accounting",4th d,pearson prentice hall, (2004), pp371-374

Klaus, Peter, Logistics as a science of networks and flows, Logist. Res.2010,p55

Pazirandeh, Ali\& Jafari, Hamid (2013): "Making sense of green logistics", International Journal of Productivity

and Performance Management, Vol. 62 Iss 8 pp. 889 - 904

Song, Hua\&Wang, Lan(2009): "The status and development of logistics cost management: evidence from Mainland China", Benchmarking: An International Journal, Vol. 16 Iss 5 pp. $657-670$ 
Rivera,Liliana\&Gligor,Daviad\&Sheffi,Yossi(2016): "the benefits of logistics clustering",international journal of physical distribution\&logistics management ,vol, 46 iss 3 pp.242268

Visser, Evert-Jan, Logistic innovation in global supply chains: an empirical test of dynamic transaction-cost theory, GeoJournal,volum 70,2008,p214

\title{
USING VALUE CHAINS TO REDUCE THE COSTS OF \\ LOGISTICS IN THE FIELD OF AIR CARGO FOR ENVIRONMENTAL PURPOSES:
}

\section{AN EMPIRICAL STUDY}

\author{
Attia, M. M. H. ${ }^{(1)}$; Ashouar, Asafat, S. A. H. ${ }^{(2)}$ \\ and Abdel Basset, W. F. ${ }^{(3)}$
}

1) Egypt Air Cargo 2) Professor of Costs Accountin, Faculty of Commerce Ain Shams University 3) Lecturer, Department of economics, Faculty of Commerce Ain Shams University

\begin{abstract}
The main objective of this research is to study the impact of the second generation of the value chain model on the logistics costs and preserve the environment of air cargo and consequently increasing the company's profits. The research hypotheses are:

1-There is a significant relationship between applying the value chain and reducing logistics costs

2- The application of value chains increases the company's profits

3- The use of value chain reduces the logistics costs

The mentioned hypotheses were tested through the data obtained from company (x), a questionnaire was constructed and sent to a sample of correspondence, In addition to the data obtained from company (x)
\end{abstract}

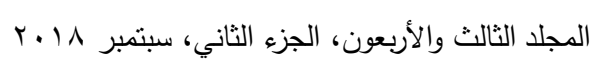


during two consecutive periods, through which the value chain cells were prepared for that company, and measuring the ability of each cell to add to the value and identifying the host cells of the value as well as the value consumed

\section{The research results:}

1 - The analysis of the value chain cells of the company (x) revealed the existence of value consuming cells and value added which requires making an analysis of the performance of both types of cells to convert the cells consuming value into adding value and to enhance the capability of the adding value cells

2- The value adding cells are the Outbound space (Table 4), and the cell of incoming spaces (Table 5),

3 - The value consuming cells are the aeronautical activity cell (Table 1 ), the cell of the outbound complexes (Table 2) and the cell of the Incoming complexes (Table 3)

The researcher also presents the issue of green logistics and its importance and the role in preserving the environment, the researcher mentioned some of the benefits of applying green logistics system to some countries, and then presented the requirements of applying this system it. 